\title{
The Effect of Musculoskeletal Pain on Sexual Function in Middle-aged and Elderly European Men: Results from the European Male Ageing Study
}

\author{
ABDELOUAHID TAJAR, TERENCE W. O'NEILL, DAVID M. LEE, DARYL B. O'CONNOR, GIOVANNI CORONA, \\ JOSEPH D. FINN, GYORGY BARTFAI, STEVEN BOONEN, FELIPE F. CASANUEVA, GIANNI FORTI, \\ ALEKSANDER GIWERCMAN, THANG S. HAN, ILPO T. HUHTANIEMI, KRZYSZTOF KULA, \\ MICHAEL E.J. LEAN, NEIL PENDLETON, MARGUS PUNAB, NITIN PURANDARE, ALAN J. SILMAN, \\ DIRK VANDERSCHUEREN, FREDERICK C.W. WU, and JOHN McBETH; the European Male Ageing Study Group
}

ABSTRACT. Objective. To determine whether musculoskeletal pain was associated with impaired sexual function in a population sample of middle-aged and older men.

Methods. The European Male Ageing Study (EMAS), a multicenter population-based study of men aged 40-79 years, was used to investigate this hypothesis. A questionnaire asked about the presence and duration of musculoskeletal pain, allowing subjects to be classified into 1 of 3 groups: those reporting chronic widespread pain (CWP), those reporting pain but not CWP ("some pain"), and those with no pain. Subjects completed a sexual function questionnaire from which 3 domains were considered: overall sexual functioning (OSF), sexual functioning-related distress (SFD), and change in sexual functioning compared to 1 year ago (CSF).

Results. A total of 3206 men [mean age 60 (SD 11) yrs] had complete data on pain status. Of these, $8.7 \%$ had CWP and $50.34 \%$ had "some pain." Pain was associated with lower OSF, and higher SFD and CSF scores. After adjustment for putative confounding factors, the associations became nonsignificant with OSF and CSF but persisted for SFD. Associations between pain status and some items within the sexual functioning domains, including frequency of sexual intercourse, frequency of morning erections, sexual desire, and orgasm were also significant, although these associations varied by pain status.

Conclusion. Musculoskeletal pain is associated with several aspects of sexual functioning. These relationships differ depending on the extent of the pain (chronic or not) and are also largely confounded by other health-related factors, primarily depression. (First Release Dec 15 2010; J Rheumatol 2011;38:370-7; doi:10.3899/jrheum.100604)

Key Indexing Terms:

CHRONIC WIDESPREAD PAIN SPIDEMIOLOGY MALE SEXUAL HEALTH POPULATION-BASED

HEALTH-RELATED QUALITY OF LIFE

From the Arthritis Research UK Epidemiology Unit and the Andrology Research Unit, Developmental and Regenerative Biomedicine Research Group, and the Psychiatry Research Group, University Place, The University of Manchester, Manchester Academic Health Science Centre and Manchester Royal Infirmary, Manchester; Institute of Psychological Sciences, University of Leeds, Leeds; Department of Endocrinology, University College London, London; Department of Surgery and Cancer, Imperial College London, Hammersmith Campus, London; School of Community Based Medicine, The University of Manchester, Salford Royal National Health Service (NHS) Trust, Salford; Arthritis Research UK, Chesterfield, UK; Endocrinology Unit, Department of Clinical Physiopathology, University of Florence, Florence, Italy; Department of Obstetrics, Gynaecology and Andrology, Albert Szent-György Medical University, Szeged, Hungary; Department of Geriatric Medicine and the Department of Andrology and Endocrinology, Katholieke Universiteit Leuven, Leuven, Belgium; Department of Medicine, Santiago de Compostela University, Complejo Hospitalario Universitario de Santiago (CHUS), and the CIBER de Fisiopatología Obesidad y Nutricion (CB06/03), Instituto Salud Carlos III, Santiago de Compostela, Spain; Reproductive Medicine Centre, Skåne University Hospital, University of Lund, Lund, Sweden; Department of Andrology and Reproductive Endocrinology, Medical University of Lodz, Lodz, Poland; Department of Human Nutrition, University of Glasgow, Glasgow, Scotland; and Andrology Unit, United Laboratories of Tartu University Clinics, Tartu, Estonia.
The European Male Ageing Study is funded by the Commission of the European Communities Fifth Framework Programme "Quality of Life and Management of Living Resources,” Grant QLK6-CT-2001-00258. A. Tajar, PhD; T.W. O'Neill, MD; D.M. Lee, PhD; Arthritis Research UK Epidemiology Unit, University of Manchester; D.B. O'Connor, PhD, Institute of Psychological Sciences, University of Leeds; G. Corona, MD, Endocrinology Unit, Department of Clinical Physiopathology, University of Florence; J.D. Finn, BSc, Andrology Research Unit, The University of Manchester; G. Bartfai, MD, Department of Obstetrics, Gynaecology and Andrology, Albert Szent-György Medical University; S. Boonen, MD, PhD, Department of Geriatric Medicine, Katholieke Universiteit Leuven; F.F. Casanueva, MD, PhD, Department of Medicine, Santiago de Compostela University, CHUS; G. Forti, MD, Endocrinology Unit, Department of Clinical Physiopathology, University of Florence; A. Giwercman, $M D, P h D$, Reproductive Medicine Centre, Skåne University Hospital, University of Lund; T.S. Han, MD, PhD, Department of Endocrinology, University College London; I.T. Huhtaniemi, MD, PhD, Department of Surgery and Cancer, Imperial College London, and Arthritis Research UK Epidemiology Unit, University of Manchester; K. Kula, MD, PhD, Department of Andrology and Reproductive Endocrinology, Medical University of Lodz; M.E.J. Lean, MD, Department of Human Nutrition, University of Glasgow; N. Pendleton, MD, School of Community Based Medicine, The University of Manchester, Salford Royal NHS Trust; M. Punab, MD, PhD, Andrology Unit, United Laboratories of Tartu University Clinics; N. Purandare, 
MD, PhD, Psychiatry Research Group, University Place, The University of Manchester; A.J. Silman, MD, Arthritis Research UK, Chesterfield;

D. Vanderschueren, $M D, P h D$, Department of Andrology and Endocrinology, Katholieke Universiteit Leuven; F.C.W. Wu, MD, Andrology Research Unit, Developmental and Regenerative Biomedicine Research Group, The University of Manchester; J. McBeth, PhD,

Arthritis Research UK Epidemiology Unit, University of Manchester, and the European Male Ageing Study Group.

Address correspondence to Dr. A. Tajar, Arthritis Research UK Epidemiology Unit, Oxford Road, The University of Manchester, Manchester M13 9PT, United Kingdom.

E-mail: abdelouahid.tajar@manchester.ac.uk

Accepted for publication October 12, 2010.

Chronic pain has been reported to have detrimental effects on sexual relations between partners ${ }^{1,2}$. Some studies ${ }^{3}$ suggest that patients with chronic pain and their partners have greater sexual difficulties compared with pain-free couples. While regional chronic pain disorders such as genital pain are linked directly to sexual functioning and are widely recognized, the relationship between musculoskeletal pain and sexual functioning is less clear. A recent review ${ }^{4}$ of the relationship between fibromyalgia, a disorder characterized by chronic pain that is widespread throughout the body (CWP), and sexual dysfunction in women reported associations with decreased sexual arousal and excitement, decreased experience of orgasm, and increased pain with intercourse.

CWP may affect sexual functioning physiologically through vulvodynia in women ${ }^{5}$ or a general lower pain tolerance in men and women ${ }^{6}$, through the induction of fear-avoidance behavior patterns ${ }^{7}$, and/or through increased rates of anxiety and/or depression ${ }^{8}$ that are apparent in individuals with chronic pain. Previous studies have focused on clinic-based samples of patients either attending chronic pain clinics or with specific medical disorders $9,10,11,12,13,14,15$. The extent to which musculoskeletal pain affects sexual functioning in the general population is unknown. In addition, pain is associated with a variety of lifestyle and health factors including smoking, low levels of physical activity, obesity, and high levels of psychological distress, particularly depression and anxiety disorders $16,17,18,19$. Many of these factors have been linked with impairment in sexual functioning ${ }^{20,21,22}$ and it is possible that they may explain any observed relationship between musculoskeletal pain and sexual function.

We hypothesized that musculoskeletal pain would be associated with sexual dysfunction in men and that the observed associations could be confounded by lifestyle and/or healthrelated factors. We tested these hypotheses in a community sample of middle-aged and elderly European men.

\section{MATERIALS AND METHODS}

Subjects. A total of 3369 men aged 40-79 years were recruited from population registers in 8 centers for participation in an observational study of aging in men - the European Male Ageing Study (EMAS). Participating centers were Manchester (UK), Leuven (Belgium), Malmö (Sweden), Tartu (Estonia), Lodz (Poland), Szeged (Hungary), Florence (Italy), and Santiago de Compostela (Spain).
Study procedure. Subjects were invited to take part by letter of invitation, which included a questionnaire that asked about musculoskeletal pain. The questionnaire also assessed various lifestyle factors including smoking and alcohol intake, and presence of cardiovascular disorders that may be associated with sexual functioning. Those subjects who were interested in participating in the study were subsequently invited to attend a clinic for further assessment, at which time subjects completed additional questionnaire instruments including the Beck Depression Inventory (BDI) to assess depressive symptoms ${ }^{23}$ and a questionnaire on sexual function ${ }^{24}$, and their height and weight were measured. Ethical approval for the study was obtained in accordance with local institutional requirements in each center. Detailed information about the design and methods has been published ${ }^{25}$.

All subjects were asked about the presence and duration of musculoskeletal pain. Those who answered positively to the question, "In the past month have you had any pain which has lasted for one day or more?", were asked to indicate the location(s) of their pain on 4-view body mannequins (front, back, and both sides). To assess duration of any reported pain, subjects were asked whether they had been aware of their pain for 3 months or more. Based on their responses, subjects were classified into 1 of the 3 pain groups: those reporting "no pain"; those reporting pain that did not satisfy criteria for CWP ("some pain"); and CWP, using the definition in the American College of Rheumatology (ACR) criteria for fibromyalgia ${ }^{26}$. The ACR criteria require pain lasting at least 3 months, both above and below the waist, on the right and left sides of the body and in the axial skeleton. This approach to the assessment of pain status has been used in previous observational studies ${ }^{27}$.

EMAS Sexual Functioning Questionnaire (SFQ). Subjects' sexual functioning and sexual health were assessed using the validated EMAS-SFQ instrument. To ensure confidentiality and encourage participation, the SFQ was self-completed in private and then placed in a sealable envelope by the participants without scrutiny by the researchers. Details of the development and validation of the EMAS-SFQ can be found elsewhere ${ }^{24}$. We used 3 domains from the EMAS-SFQ in our analysis: "overall sexual functioning" (OSF), "sexual function-related distress" (SFD), and "change in sexual functioning" (CSF) compared to 1 year earlier. Each of the 3 questionnaire domains is based on 5 self-report items. Items in the OSF scale include frequency of sexual thoughts, sexual intercourse, petting, morning erection, and orgasm. SFD items include worrying about frequency of desire, sexual intercourse, erection, morning erection, and orgasm; and CSF items include change in desire, sexual intercourse, erection, morning erection, and orgasm (Appendix Table 1). For the original continuous scores, low values on the OSF and higher scores on the SFD and CSF represent poorer sexual functioning. For the ordinal logistic models, the items were reordered and some categories were grouped so that for all items, higher scores represent poorer sexual functioning.

Data manipulation and statistical analysis. Smoking status was categorized as either current or ever/never smoker. Alcohol intake was categorized as either 5 days per week or more, or fewer than 5 days per week. Subjects were classified according to whether they self-reported any cardiovascular symptoms (yes vs no). Age (years) and BDI were considered as continuous variables. One item, "loss of interest in sex," was excluded from the BDI score because the nature of the outcome would likely lead to spurious associations. Body mass index [BMI; weight $(\mathrm{kg})$ divided by height squared (m)] was calculated.

Descriptive statistics were used to characterize the occurrence of pain, sexual function variables, and other subject characteristics, with results presented as mean and SD for continuous variables and number and percentage for discrete variables. The associations between pain status and sexual function scores and factors that could potentially confound the relationships between them were explored using multiple linear regression models. In all models the sexual function variables were the outcomes. Three models were constructed: model 1 adjusted for age; model 2 adjusted for age, center, BMI, smoking and alcohol use, and cardiovascular symptoms; and model 3 adjusted for all variables in model 2 plus BDI for OSF and CSF scores only. 
Table 1. Baseline characteristics in the entire analysis sample and by pain status. Data are mean (SD).

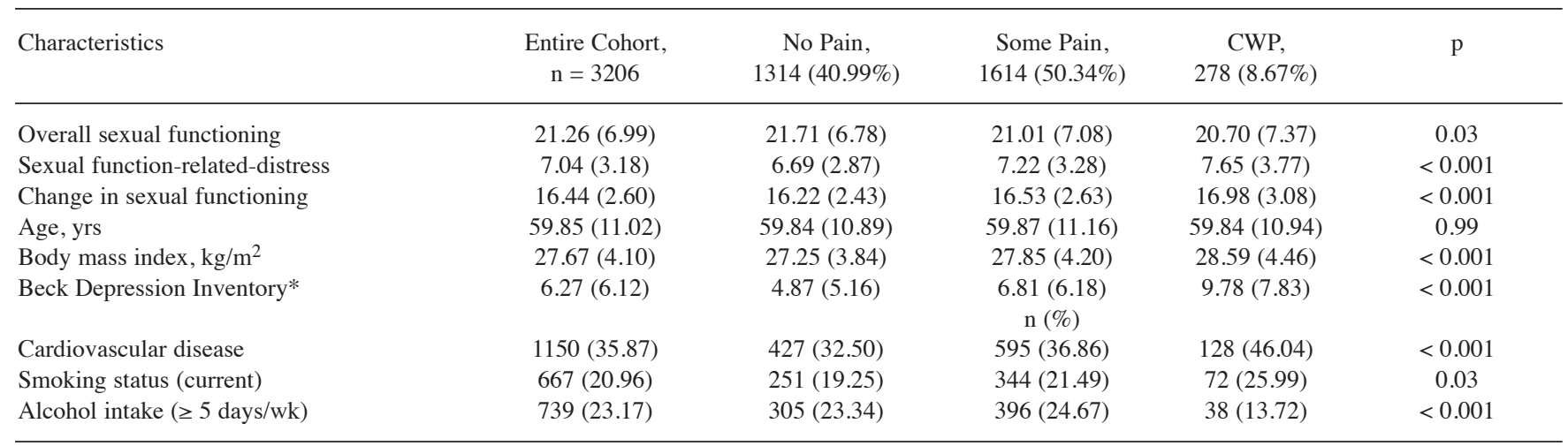

* The item "loss of interest in sex" was excluded from the Beck Depression Inventory. P value: ANOVA for continuous variables, chi-square test for discrete variables. CWP: chronic widespread pain.

Multivariable ordinal logistic regression models were used to further explore the associations between the individual sexual function items (dependent variables) and pain status. For the purpose of these analyses, each individual item was recorded as an ordinal variable with 3 categories (Appendix Tables 2A-C), with higher values corresponding to poorer sexual function.

Results from the multiple linear regression models were expressed as $\beta$ coefficients with $95 \% \mathrm{CI}$, and results from the ordinal regression models were expressed as OR with $95 \%$ CI. Robust standard errors that give reliable estimates of the association between pain status and sexual function were used in the regression models to adjust for research center and to take into account the hierarchy of the study design (individuals nested within centers). All statistical analyses were conducted using Intercooled Stata version 9.2 (StataCorp, College Station, TX, USA).

\section{RESULTS}

A total of $3206(95.16 \%)$ out of 3369 men who participated in the EMAS study had complete data on pain status and were used in the current analysis. The mean age was 60 years (SD 11 yrs). Mean BMI was $27.67 \mathrm{~kg} / \mathrm{m}^{2}$ (SD 4.10). Presence of cardiovascular disorders was reported by $35.87 \%$ of subjects, $20.96 \%$ were current smokers, and $23.17 \%$ drank alcohol at least 5 days per week. The mean score for BDI was 6.27 (SD 6.12; Table 1).

Among men included in this analysis, 278 (8.67\%) had CWP, 1614 (50.34\%) had some pain although not CWP, and 1314 (40.99\%) had no pain. As shown in Table 1, reporting some pain and CWP was associated with lower OSF (i.e., poorer) scores and higher (i.e., poorer) SFD and CSF scores. Compared to subjects with no pain, those with some pain had significantly higher BMI and BDI scores $(\mathrm{p}<0.001$ for all comparisons), with scores even higher among the CWP group. Reporting pain was also associated with self-reported cardiovascular disease (CVD; $\mathrm{p}<0.001)$ and being a current smoker $(\mathrm{p}<0.05)$, while those with CWP were significantly less likely to consume alcohol at least 5 days per week ( $\mathrm{p}<0.001$; Table 1).

Table 2 summarizes the results of the linear regression analysis, examining the relationship between nonpain variables and sexual function scores that could potentially confound the relationship between pain status and sexual functioning scores. Age, BMI, BDI, and CVD were significantly associated with lower levels of OSF and higher levels of SFD and CSF. The association was particularly strong in those with CVD. Being a current smoker and consuming alcohol at least 5 days per week were significantly associated with higher OSF scores but not SFD and CSF scores.

Pain status and sexual function domains. After adjusting for age, having some pain was associated with lower OSF and higher SFD and CSF scores (Table 3). Subsequent analyses found the relationship between some pain and OSF scores was confounded by the effects of age $(\beta=-0.34,95 \% \mathrm{CI}$

Table 2. Determinants of sexual function scores: linear regression analyses. Data are $\beta(95 \% \mathrm{CI})$.

\begin{tabular}{lccc}
\hline & OSF & SFD & CSF \\
\hline Age, yrs & $-0.35(-0.37,-0.33)^{* * *}$ & $0.03(0.02,0.04)^{* * *}$ & $0.07(0.06,0.08)^{* * *}$ \\
BMI, kg/m & $-0.10(-0.17,-0.04)^{* *}$ & $0.05(0.02,0.08)^{* * *}$ & $0.03(0.004,0.05)^{*}$ \\
BDI & $-0.26(-0.31,-0.22)^{* * *}$ & $0.16(0.14,0.18)^{* * *}$ & $0.10(0.09,0.12)^{* * *}$ \\
Cardiovascular disease & $-3.64(-4.20,-3.08)^{* * *}$ & $0.73(0.48,0.98)^{* * *}$ & $0.84(0.64,1.04)^{* * *}$ \\
Smoking status (current) & $0.79(0.11,1.46)^{*}$ & $0.29(-0.01,0.58)$ & $-0.15(-0.39,0.08)$ \\
Alcohol intake ( $\geq 5$ days/wk) & $1.50(0.86,2.15)^{* * *}$ & $0.03(-0.24,0.31)$ & $0.05(-0.17,0.28)$ \\
\hline
\end{tabular}

OSF: overall sexual functioning; SFD: sexual function-related distress; CSF: change in sexual functioning; BMI: body mass index; BDI: Beck Depression Inventory (the item "loss of interest in sex" was excluded from the BDI). $* \mathrm{p}<0.05, * * \mathrm{p}<0.01, * * * \mathrm{p}<0.001$. 
Table 3. Association between sexual function scores and pain status: multiple linear regression analyses. Data are B (95\% CI). Referent: no pain.

\begin{tabular}{|c|c|c|c|c|c|c|c|c|}
\hline & \multicolumn{3}{|c|}{ OSF } & \multicolumn{2}{|c|}{ SFD } & \multicolumn{3}{|c|}{ CSF } \\
\hline & Adjusted (i) & Adjusted (ii) & Adjusted (iii) & Adjusted (i) & Adjusted (ii) & Adjusted (i) & Adjusted (ii) & Adjusted (iii) \\
\hline Some pain & $\begin{array}{c}-0.67 \\
(-1.16,-0.18)^{* *}\end{array}$ & $\begin{array}{c}-0.65 \\
(-1.35,0.05)\end{array}$ & $\begin{array}{c}-0.32 \\
(-1.03,0.40)\end{array}$ & $\begin{array}{c}0.52 \\
(0.27,0.77)^{* * *}\end{array}$ & $\begin{array}{c}0.48 \\
(0.06,0.90)^{*}\end{array}$ & $\begin{array}{c}0.31 \\
(0.11,0.50)^{* *}\end{array}$ & $\begin{array}{c}0.29 \\
(0.15,0.43)^{* *}\end{array}$ & $\begin{array}{c}0.14 \\
(-0.003,0.29)\end{array}$ \\
\hline CWP & $\begin{array}{c}-0.84 \\
(-1.68,0.01)\end{array}$ & $\begin{array}{c}-0.46 \\
(-1.50,0.58)\end{array}$ & $\begin{array}{c}0.44 \\
(-0.60,1.49)\end{array}$ & $\begin{array}{c}0.96 \\
(0.52,1.40)^{* * *}\end{array}$ & $\begin{array}{c}0.87 \\
(0.29,1.46)^{*}\end{array}$ & $\begin{array}{c}0.77 \\
(0.42,1.11)^{* * *}\end{array}$ & $\begin{array}{c}0.72 \\
(0.45,1.00)^{* * * *}\end{array}$ & $\begin{array}{c}0.36 \\
(-0.01,0.74)\end{array}$ \\
\hline
\end{tabular}

Model (i) adjusted for age. Model (ii) as for model (i) plus body mass index, cardiovascular disease, smoking status, alcohol intake, and research center. Model (iii) as for model (ii) plus BDI for OSF and CSF only. OSF: overall sexual functioning; SFD: sexual function-related distress; CSF: change in sexual functioning; CWP: chronic widespread pain; BDI: Beck Depression Inventory. $* \mathrm{p}<0.05$, ** $\mathrm{p}<0.01, * * * \mathrm{p}<0.001$. Referent: no pain.

$-0.40,-0.27)$, alcohol intake $(\beta=1.68,95 \%$ CI $0.61,2.76)$, and BDI score $(B=-0.20,95 \% \mathrm{CI}-0.23,-0.17)$. The relationships with both SFD and CSF scores persisted after adjustments for age, alcohol intake, BMI, CVD, and center effects. However, the relationships with CSF became nonsignificant after further adjustment for levels of depression.

Compared to those subjects with no pain, having CWP was not associated with OSF scores. CWP was significantly associated with higher SFD and CSF scores. After adjustment for age, alcohol intake, BMI, CVD, and center effects, the relationships between CWP and SFD and CSF remained, although further adjustment of the relationship with CSF scores for levels of depression reduces the relationship and makes it no longer significant. In that final model, age ( $\beta=$ $0.06,95 \%$ CI $0.04,0.08)$ and BDI $(\beta=0.09,95 \%$ CI 0.05 , 0.13) were associated with CSF scores.

Pain status and sexual function items. When the relationships among pain status and the specific items within the sexual functioning domains were examined (adjusted for potential confounders, Figure 1A-C), the observed relationships appeared to be driven by specific associations. Among men who reported some pain, the main association within the items of the OSF scale was with problems related to thinking about sex (Figure 1A); 4 out of 5 items of the SFD scale were associated with the presence of some pain (Figure 1B); and 1 item (change in the frequency of morning erections) of the CSF scale (Figure 1C) was also significantly associated with the presence of some pain. Although CWP was not significantly associated with total OSF scores, these men had better scores on the frequency of morning erections item (Figure 1A); 2 out of 5 items of the SFD scale were significantly associated with the presence of CWP (Figure 1B); and the CSF scale item "change in desire" was significantly (but weakly) associated with CWP (Figure 1C).

Only distress related to sexual desire was associated with both some pain and CWP. The relationships between sexual function and pain status were different depending on the extent of the pain (chronic or not) and were also largely confounded by other health-related factors, mainly depression.

\section{DISCUSSION}

Ours is the first population-based study to show a significant association between pain and overall sexual functioning, sexual functioning-related distress, and change in sexual functioning among middle-aged and older European men. These associations were mainly explained by age, alcohol consumption, and higher levels of depression.

Our results are consistent with data from studies of clinic patients with chronic pain that have shown chronic pain to be associated with impaired sexual functioning $9,11,12,15,28,29$. Some studies suggest that this association may in part be explained by psychological factors, mainly depression ${ }^{10,28}$. In our study, levels of depression were robustly associated with OSF and CSF scores and depression appeared to confound the relationship between pain and these dimensions of sexual functioning. Previous clinic-based studies ${ }^{15}$ suggest that despite impaired sexual function, many patients report no loss of satisfaction with sex or with their relationship, suggesting adaptation to changed circumstances.

There are potentially important clinical implications of our findings. Musculoskeletal pain disorders are normally treated by rheumatologists, physiotherapists, and in extreme cases, orthopedic surgeons. These specialists are not routinely trained in sexual health medicine ${ }^{30}$ and may fail to recognize the important link between chronic musculoskeletal pain and sexual functioning. Individuals from the general population with CWP are more likely to experience impaired sexual functioning/greater sexual function distress and changes in sexual function, in a similar fashion to clinic patients. Our data show that certain lifestyle, physical, and psychological factors confound these associations. It is clear that not all individuals with pain will have impaired sexual function; however, these data suggest that those with additional factors are at increased risk of not adapting to changed circumstances. These findings suggest the need for a holistic/comprehensive assessment of individuals with pain that would include an assessment of different aspects of sexual function and an assessment of other health factors including lifestyle factors and levels of depression that are likely to increase the risk of a poor sexual function outcome. Such assessment would enable appropriate individualized management to be offered. Among these patients, recognition that impaired sexual function may be an associated but undeclared clinical problem may also improve the doc-

Personal non-commercial use only. The Journal of Rheumatology Copyright @ 2011 . All rights reserved. 

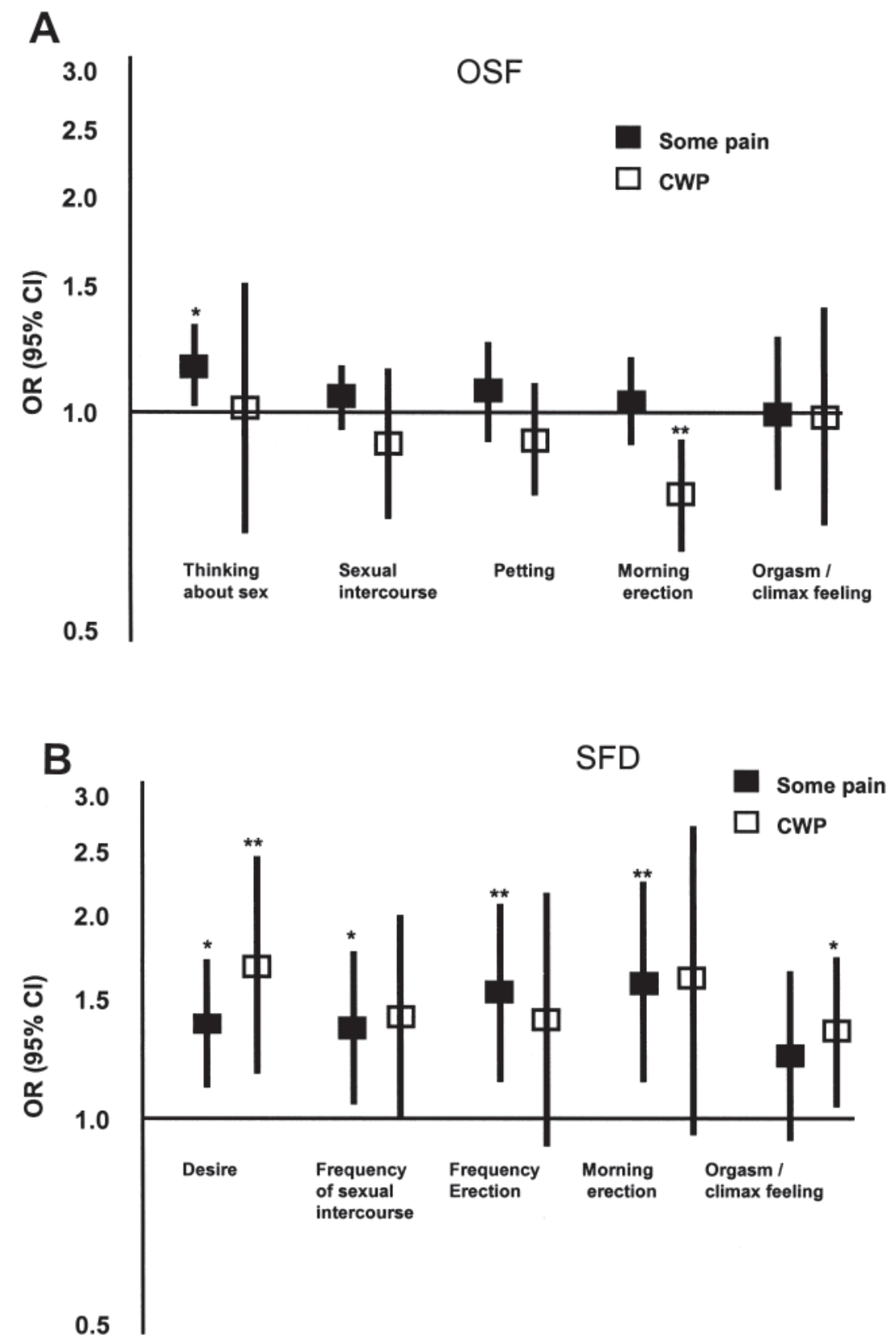

Figure 1. Associationa between items of sexual function scores and pain status. (A) For overall sexual functioning (OSF) items: Models were adjusted for age, body mass index, cardiovascular disease, smoking status, alcohol intake, depression, and medical center. Significant associations were thinking about sex: *some pain (OR 1.16, 95\% CI 1.02,1.33) and morning erection: **chronic widespread pain (CWP; OR 0.77, 95\% CI 0.64, 0.92). (B) For sexual function-related-distress (SFD) items: Models were adjusted for age, body mass index, cardiovascular disease, smoking status, alcohol intake, and medical center. Significant associations were desire: *some pain (OR 1.38, 95\% CI 1.11, 1.72) and $* *$ CWP (OR 1.68, 95\% CI 1.17, 2.43); frequency of sexual intercourse: *some pain (OR 1.36, $95 \%$ CI 1.05, 1.76); frequency of erection: ** some pain (OR 1.54, 95\% CI 1.13, 2.08); morning erection: **some pain (OR 1.59, 95\% CI 1.13, 2.23); orgasm: *CWP (OR 1.35, 95\% CI 1.04, 1.72).

tor-patient relationship, leading to better outcomes for patients. Musculoskeletal pain is more common in women, and to date the majority of studies have focused on the relationship between pain and sexual functioning in women.
Our study shows that in the general population, not only are musculoskeletal pain symptoms common in men, but that they also affect sexual functioning, an important aspect of well-being and quality of life. 


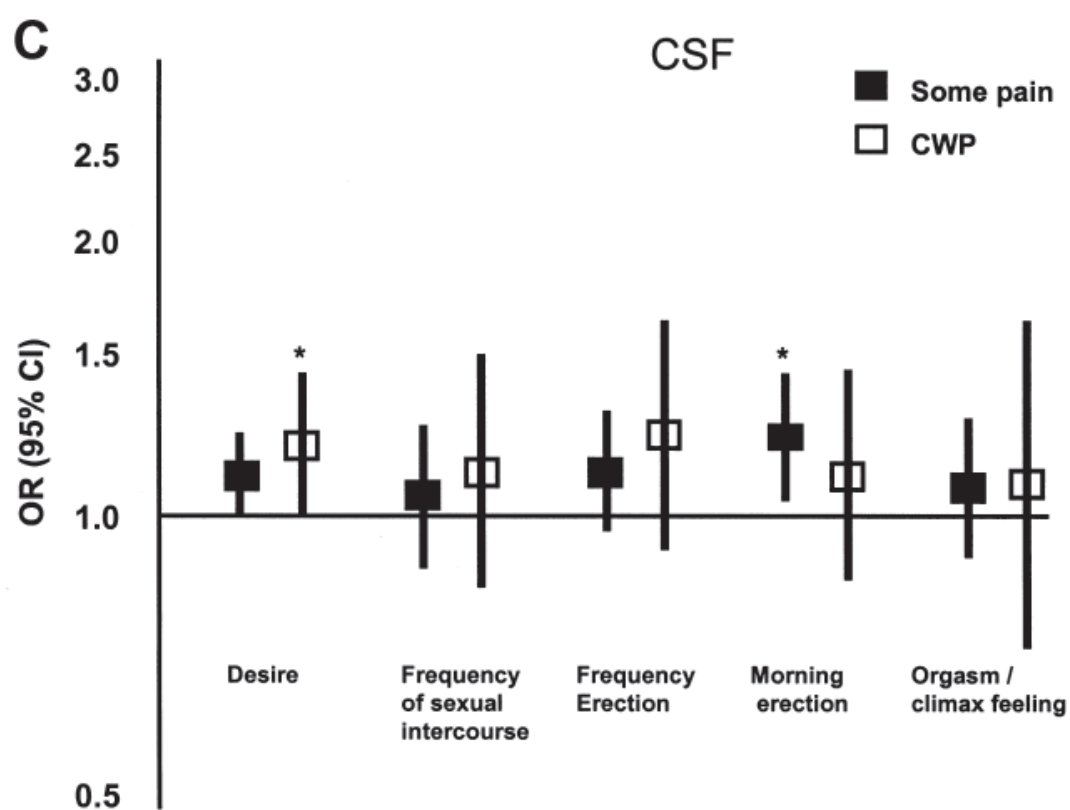

Figure 1. (C) For change in sexual functioning (CSF) items: Models were adjusted for age, body mass index, cardiovascular disease, depression, and research center. Significant associations were desire: $*$ CWP (OR 1.19, 95\% CI 1.001, 1.43); and morning erection: *some pain (OR $1.22,95 \%$ CI $1.04,1.43) . * \mathrm{p}<0.05, * * \mathrm{p}<0.01, * * * \mathrm{p}<0.001$. Referent: no pain.

Our study has a number of strengths. Standardized methods were used in both the design and conduct of the study in the different participating centers and in the instruments used to assess both pain and sexual function ${ }^{25}$. There are, however, some limitations that need to be considered in interpreting the results. The response rate for participation in the study was $41 \%$. Those who participated may have differed in the frequency of pain and/or sexual functioning from those who did not participate and some caution, therefore, is needed in interpreting these data. More importantly, we do not know whether the relationship between having pain and sexual functioning outcomes was different in those who did and did not participate and whether we have consequently overestimated the strength of the observed relationships. Our study was cross-sectional and it is not possible to determine the temporal nature of the observed associations, for which prospective data are required. Finally, the results were obtained from a predominantly white, European population and should be extrapolated beyond this setting with care.

The occurrence of CWP among men in middle age and later life was associated with impairment in sexual functioning. This relationship was confounded by health and lifestyle factors. We suggest that a comprehensive assessment of health-related quality of life in subjects with musculoskeletal pain should include an assessment of sexual function.

\section{ACKNOWLEDGMENT}

The authors thank the men who participated in the 8 countries and the research/nursing staff in the 8 centers: C. Pott, Manchester; E. Wouters, Leuven; M. Nilsson, Malmö; M. del Mar Fernandez, Santiago de Compostela; M. Jedrzejowska, Lodz; H-M. Tabo, Tartu; and A. Heredi,
Szeged, for their meticulous data collection, and C. Moseley, Manchester, for data entry and project coordination. Support from the National Institute for Health Research Manchester Biomedical Research Center and Arthritis Research UK is acknowledged.

\section{APPENDIX}

The study collaborators (the EMAS Group): Florence, Luisa Petrone; Leuven, Herman Borghs; Lodz, Jolanta Slowikowska-Hilczer, Renata Walczak-Jedrzejowska; Manchester, Philip Steer, Stephen Pye; Santiago de Compostela, Mary Lage; Szeged, Imre Földesi, Imre Fejes; Tartu, Paul Korrovitz; Turku, Min Jiang.

\section{REFERENCES}

1. Payne B, Norfleet MA. Chronic pain and the family: A review. Pain 1986;26:1-22.

2. Corona G, Petrone L, Mannucci E, Magini A, Lotti F, Ricca V, et al. Assessment of the relational factor in male patients consulting for sexual dysfunction: the concept of couple sexual dysfunction. J Androl 2006;27:795-801.

3. Maruta T, Osborne D, Swanson DW, Halling JM. Chronic pain patients and spouses: Marital and sexual adjustment. Mayo Clin Proc 1981;56:307-10.

4. Kalichman L. Association between fibromyalgia and sexual dysfunction in women. Clin Rheumatol 2009;28:365-9.

5. Arnold LD, Bachmann GA, Rosen R, Rhoads GG. Assessment of vulvodynia symptoms in a sample of US women: A prevalence survey with a nested case control study. Am J Obstet Gynecol 2007;196:128 e1-6.

6. Gupta A, Silman AJ, Ray D, Morriss R, Dickens C, MacFarlane GJ, et al. The role of psychosocial factors in predicting the onset of chronic widespread pain: results from a prospective population-based study. Rheumatology 2007;46:666-71.

7. Vangronsveld K, Van Damme S, Peters M, Vlaeyen J, Goossens M, Crombez G. An experimental investigation on attentional interference by threatening fixations of the neck in patients with

Personal non-commercial use only. The Journal of Rheumatology Copyright @ 2011. All rights reserved. 
Appendix table 1. Sexual function domains and items.

\begin{tabular}{ll}
\hline Sexual Domains & Items \\
\hline OSF: Overall sexual functioning & How often do you think about sex? \\
& How many times have you attempted sexual intercourse? \\
& How often do you engage in kissing, fondling, petting, etc.? \\
& How frequently did you awaken with a full erection? \\
& How often did you have the feeling of orgasm or climax? \\
SFD: Sexual functioning-related distress & Worried or distressed by current level of sexual drive/desire? \\
& Worried or distressed by frequency of sexual activities? \\
& Worried or distressed by ability to have an erection? \\
& Worried or distressed by frequency of morning erections? \\
& Worried or distressed by current orgasmic experience? \\
CSF: Change in sexual functioning, & Sexual drive/desire changed? \\
compared with a year ago & Frequency of sexual activities changed? \\
& Ability to have erection changed? \\
& Frequency of morning erections changed? \\
& Has the orgasmic enjoyment changed? \\
\hline
\end{tabular}

Appendix table 2A. Overall sexual functioning - categories and prevalence of items.

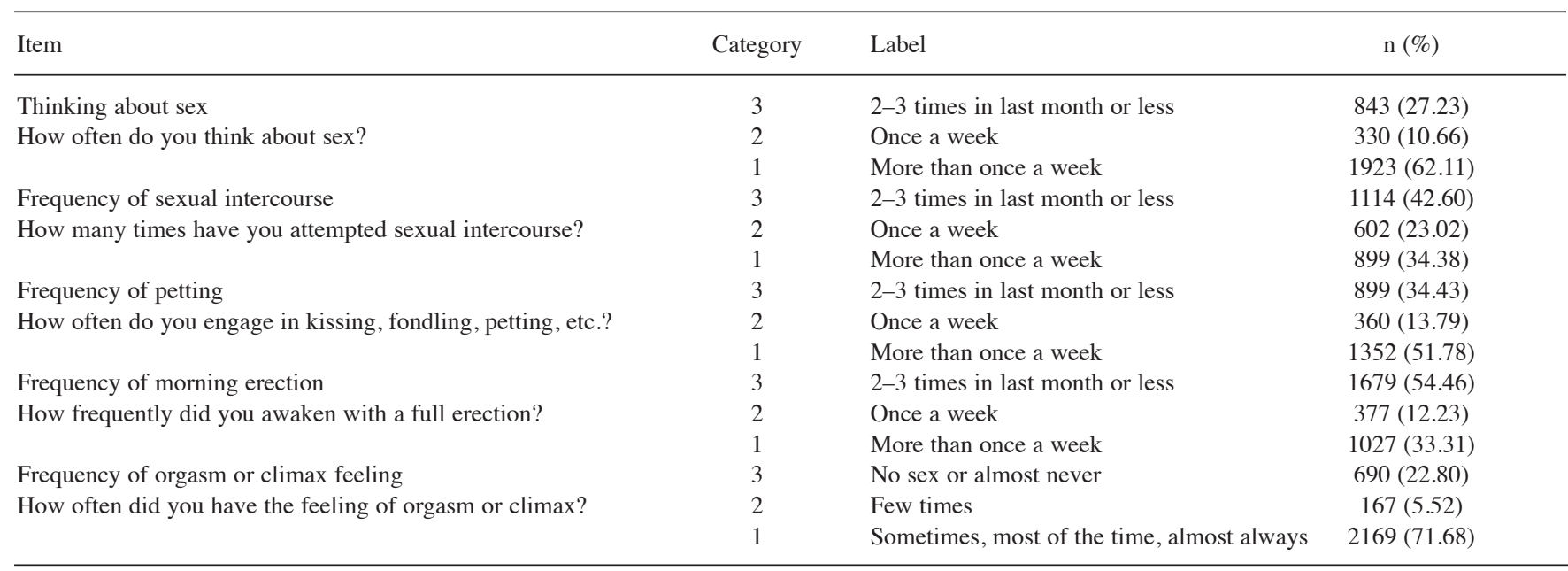

Appendix table $2 B$. Sexual functioning-related distress - categories and prevalence of items.

\begin{tabular}{|c|c|c|c|}
\hline Item & Category & Label & $\mathrm{n}(\%)$ \\
\hline Desire & 3 & Very or extremely & $89(2.88)$ \\
\hline Worried or distressed by current level of sexual drive/desire? & 2 & Moderately & $274(8.86)$ \\
\hline Frequency of sexual intercourse & 3 & Very or extremely & $101(3.43)$ \\
\hline \multirow[t]{2}{*}{ Worried or distressed by frequency of sexual activities? } & 2 & Moderately & $249(8.46)$ \\
\hline & 1 & Not at all or a little bit & $2592(88.10)$ \\
\hline Worried or distressed by ability to have an erection? & 1 & Not at all or a little bit & $2642(85.70)$ \\
\hline Morning erection & 3 & Very or extremely & $48(1.60)$ \\
\hline \multirow[t]{2}{*}{ Worried or distressed by frequency of morning erections? } & 2 & Moderately & $113(3.76)$ \\
\hline & 1 & Not at all or a little bit & $2846(94.65)$ \\
\hline Orgasm or climax feeling & 3 & High: Very or extremely & $101(3.40)$ \\
\hline Worried or distressed by current orgasmic experience? & 2 & Medium: Moderately & $318(10.70)$ \\
\hline
\end{tabular}


Appendix table $2 C$. Change in sexual functioning, compared with a year ago - categories and prevalence of items.

\begin{tabular}{lllc}
\hline Item & Category & Label & $\mathrm{n}(\%)$ \\
\hline Desire & 3 & Decreased & $931(30.20)$ \\
Sexual drive/desire changed. & 2 & Same & $2048(66.43)$ \\
& 1 & Increased & $104(3.37)$ \\
Frequency of sexual intercourse & 3 & Decreased & $1028(33.72)$ \\
Frequency of sexual activities changed? & 2 & Same & $1924(63.10)$ \\
& 1 & Increased & $97(3.18)$ \\
Frequency of erection & 3 & Decreased & $811(26.50)$ \\
Ability to have erection changed? & 2 & Same & $2175(71.08)$ \\
& 1 & Increased & $74(2.42)$ \\
Morning erection & 3 & Decreased & $650(21.75)$ \\
Frequency of morning erection changed? & 2 & Same & $2266(75.81)$ \\
& 1 & Increased & $73(2.44)$ \\
Orgasm or climax feeling & 3 & Decreased & $585(19.66)$ \\
Has the orgasmic enjoyment changed? & 2 & Same & $2267(76.20)$ \\
& 1 & Increased & $123(4.13)$ \\
\hline
\end{tabular}

chronic whiplash syndrome. Pain 2007;127:121-8.

8. Orellana C, Gratacos J, Galisteo C, Larrosa M. Sexual dysfunction in patients with fibromyalgia. Curr Rheumatol Rep 2009;11:437-42.

9. Monga TN, Tan G, Ostermann HJ, Monga U, Grabois M. Sexuality and sexual adjustment of patients with chronic pain. Disabil Rehabil 1998;20:317-29.

10. Aydin G, Basar MM, Keles I, Ergun G, Orkun S, Batislam E. Relationship between sexual dysfunction and psychiatric status in premenopausal women with fibromyalgia. Urology 2006;67:156-61.

11. Shaver JL, Wilbur J, Robinson FP, Wang E, Buntin MS. Women's health issues with fibromyalgia syndrome. J Womens Health (Larchmt) 2006;15:1035-45.

12. Abdel-Nasser AM, Ali EI. Determinants of sexual disability and dissatisfaction in female patients with rheumatoid arthritis. Clin Rheumatol 2006;25:822-30.

13. van Berlo WT, van de Wiel HB, Taal E, Rasker JJ, Weijmar Schultz WC, van Rijswijk MH. Sexual functioning of people with rheumatoid arthritis: A multicenter study. Clin Rheumatol 2007;26:30-8

14. Frohlich P, Meston C. Sexual functioning and self-reported depressive symptoms among college women. J Sex Res 2002;39:321-5.

15. Smith KB, Pukall CF, Tripp DA, Nickel JC. Sexual and relationship functioning in men with chronic prostatitis/chronic pelvic pain syndrome and their partners. Arch Sex Behav 2007;36:301-11.
16. Yunus MB, Arslan S, Aldag JC. Relationship between fibromyalgia features and smoking. Scand J Rheumatol 2002;31:301-5.

17. Kop WJ, Lyden A, Berlin AA, Ambrose K, Olsen C, Gracely RH, et al. Ambulatory monitoring of physical activity and symptoms in fibromyalgia and chronic fatigue syndrome. Arthritis Rheum 2005;52:296-303.

18. Arnold LM, Hudson JI, Keck PE, Auchenbach MB, Javaras KN, Hess EV. Comorbidity of fibromyalgia and psychiatric disorders. J Clin Psychiatry 2006;67:1219-25.

19. Hooper MM, Stellato TA, Hallowell PT, Seitz BA, Moskowitz RW. Musculoskeletal findings in obese subjects before and after weight loss following bariatric surgery. Int J Obes (Lond) 2007;31:114-20.

20. Bacon CG, Mittleman MA, Kawachi I, Giovannucci E, Glasser DB, Rimm EB. Sexual function in men older than 50 years of age: Results from the health professionals follow-up study. Ann Intern Med 2003;139:161-8.

21. Esposito K, Giugliano F, Di Palo C, Giugliano G, Marfella R, D'Andrea F, et al. Effect of lifestyle changes on erectile dysfunction in obese men: a randomized controlled trial. JAMA 2004;291:2978-84.

22. Corona G, Ricca V, Bandini E, Mannucci E, Petrone L, Fisher AD, et al. Association between psychiatric symptoms and erectile dysfunction. J Sex Med 2008;5:458-68.

23. Beck AT, Ward CH, Mendelson M, Mock J, Erbaugh J. An inventory for measuring depression. Arch Gen Psychiatry 1961;4:561-71.

24. O'Connor DB, Corona G, Forti G, Tajar A, Lee DM, Finn JD, et al. Assessment of sexual health in aging men in Europe: development and validation of the European Male Ageing Study sexual function questionnaire. J Sex Med 2008;5:1374-85.

25. Lee DM, O’Neill TW, Pye SR, Silman AJ, Finn JD, Pendleton N, et al. The European Male Ageing Study (EMAS): design, methods and recruitment. Int J Androl 2009;32:11-24.

26. Wolfe F, Smythe HA, Yunus MB, Bennett RM, Bombardier C, Goldenberg DL, et al. The American College of Rheumatology 1990 Criteria for the Classification of Fibromyalgia. Report of the Multicenter Criteria Committee. Arthritis Rheum 1990;33:160-72.

27. McBeth J, Macfarlane GJ, Benjamin S, Silman AJ. Features of somatization predict the onset of chronic widespread pain: results of a large population-based study. Arthritis Rheum 2001;44:940-6.

28. Kwan KS, Roberts LJ, Swalm DM. Sexual dysfunction and chronic pain: the role of psychological variables and impact on quality of life. Eur J Pain 2005;9:643-52.

29. Ambler N, Williams AC, Hill P, Gunary R, Cratchley G. Sexual difficulties of chronic pain patients. Clin J Pain 2001;17:138-45.

30. Rosenbaum TY. Musculoskeletal pain and sexual function in women. J Sex Med 2010;7:645-53. 